\title{
Outcome of complex tibial pilon fractures definitively treated with external fixator
}

\author{
Meryem Lemsanni*, Youssef Najeb, Rachid Chafik, \\ Mohamed Madhar, Hanane Elhaoury
}

Department of Orthopaedic and Trauma Surgery, Ibn Tofail Hospital, Mohammed VI University Hospital Center, Abdelouahab Derraq Street, Marrakesh, Morocco

Received: 13 August 2020

Accepted: 17 September 2020

\section{*Correspondence:}

Dr. Meryem Lemsanni,

E-mail: lemsani.meryam@hotmail.com

Copyright: ( ) the author(s), publisher and licensee Medip Academy. This is an open-access article distributed under the terms of the Creative Commons Attribution Non-Commercial License, which permits unrestricted non-commercial use, distribution, and reproduction in any medium, provided the original work is properly cited.

\section{ABSTRACT}

Background: Complex tibial pilon fractures are typically sustained with high-energy mechanisms and they are often associated with severe soft tissue compromise that can frequently results in severe complications. The purpose of this prospective case series was to evaluate the radiological and clinical outcomes after the use of external fixation combined with minimally invasive osteosynthesis, as primary and definitive treatment of complex tibial pilon fractures.

Methods: A prospective study was undertaken during the period from March 2012 to June 2016. A total number of 109 patients with complex tibial pilon fractures were managed in our institution and included in the study. All the patients were treated with external fixation and minimally invasive osteosynthesis. The mean follow-up period was 47 months (31-60 months). Clinico-radiological progression of fracture union as well as the functional outcome were studied.

Results: Eighty fractures resulted from traffic accidents and type 43-C3 fracture according to AO/OTA classification was the most common. Seventy-eight were open fractures and 94 patients had associated distal fibular fractures. All patients were treated with monolateral external fixators for definitive management. The average time to union was 14 weeks (range 9-19). Eleven patients (10\%) suffered superficial pin tract infection. One patient developed septic arthritis and evidence of radiological osteoarthritis was present in ten cases (9\%) at final follow-up. The American orthopaedic

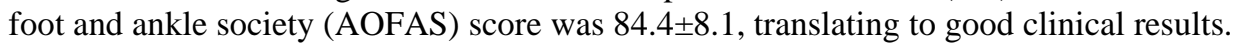

Conclusions: This review concludes that external fixation, combined with minimally invasive osteosynthesis, consistently produces good functional results without serious complications.

Keywords: Pilon fracture, External fixation, Minimally invasive osteosynthesis, High energy mechanism

\section{INTRODUCTION}

Complex tibial pilon fractures are usually high energy injuries presenting with significant articular and soft tissue damage. ${ }^{1,2}$ The management of such injuries is a surgical challenge, even for experienced orthopedic trauma surgeons. The principles of treatment include respect for the soft tissues, restoring the congruity of the articular surface and reduction of the anatomic alignment of the lower limb to enable early movement of the ankle joint. ${ }^{3}$
Although, in the past, internal fixation has been used commonly, external fixation has become a popular method of treatment in recent years, with a number of publications suggesting that satisfactory results can be obtained. ${ }^{4,5}$ In the present study, we aimed to evaluate the radiological and clinical outcomes after the use of external fixation combined with minimally invasive osteosynthesis, as primary and definitive treatment of complex tibial pilon fractures. 


\section{METHODS}

\section{Patients}

A 5-year prospective study was carried out between March 2012 and June 2016 on trauma patients with complex tibial pilon fractures at a tertiary orthopedic and traumatology hospital.

\section{Inclusion criteria}

Inclusion criteria were (1) patient age $\geq 16$ years with (2) AO/OTA types $43 \mathrm{C} 2$ and $\mathrm{C} 3$ tibial pilon fractures treated by (3) external fixation and minimally invasive osteosynthesis. Patients with AO/OTA Type 43 A, B and $\mathrm{C} 1$ fractures, patients whose fractures had been managed nonoperatively or treated by open reduction and internal fixation were excluded from the study.

The parameters analyzed included age, gender, injured side, trauma mechanism, neurovascular status of the fractured leg, associated injuries, AO/OTA classification, Gustilo and Anderson classification, time to definitive treatment, postoperative rehabilitation, antibiotic prophylaxis, and postoperative complications.

One hundred nine patients who fulfilled the inclusion criteria were enrolled in this study. The mean age was 28 years (range 19 to 71 ). There were 91 males and 18 females. The right ankle was affected in $58 \%$ of cases. Eighty patients were injured in a traffic accident, and 29 experienced a fall from a high place.

The fractures were classified on the basis of the AO/OTA classification (Table 1). There were 39 AO/OTA type 43 $\mathrm{C} 2$ and 70 type $\mathrm{C} 3$.

Table 1: AO/OTA classification of tibial pilon fractures.

\begin{tabular}{|ll|}
\hline Type & Description \\
\hline 43-A & Extra-articular fracture \\
\hline 43-A1 & -Simple \\
\hline 43-A2 & -Wedge \\
\hline 43-A3 & -Complex \\
\hline 43- B & Partial articular fracture \\
\hline 43-B1 & -Pure split \\
\hline 43-B2 & -Split-depression \\
\hline 43-B3 & -Multi fragmentary depression \\
\hline 43-C & Complete articular fracture \\
\hline 43-C1 & -Articular simple, metaphyseal simple \\
\hline 43-C2 & -Articular simple, metaphyseal multi \\
& fragmentary \\
\hline 43-C3 & -Articular multi fragmentary \\
\hline
\end{tabular}

Soft tissue injuries were classified by the GustiloAnderson classification (Table 2) and there were 78 (71\%) open fractures: 27 Gustilo-Anderson type II, 31 GustiloAnderson type IIIA and 20 type IIIB (Figure 1). Distal fibular fractures were the most common lesion associated in 94 patients $(86 \%)$. The mean time from injury to surgery was about 6 hours (2-10) for open fractures and 36 hours (16-72) in closed cases.

Antibiotic prophylaxis (intravenous Cefazolin $2 \mathrm{~g}$ ) was administered at the time of induction of anesthesia in the patients with closed fractures and it was continued for $24 \mathrm{~h}$. In patients with open fractures, $2 \mathrm{~g}$ of ceftriaxone and an aminoglycoside were administered in the emergency room. Prophylaxis was continued for 5 days. Tetanus prophylaxis and active tetanus immunization were also given.

Table 2: Gustilo-Anderson classification system for open fractures.

\begin{tabular}{|ll|}
\hline Type & Characteristics \\
\hline I & $\begin{array}{l}\text { Puncture wound }<1 \mathrm{~cm} \\
\text { Minimal contamination } \\
\text { Minimal soft tissue damage }\end{array}$ \\
\hline II & $\begin{array}{l}\text { Laceration }>1 \mathrm{~cm} \text { but }<10 \mathrm{~cm} \\
\text { Moderate soft tissue damage } \\
\text { Adequate bone coverage } \\
\text { Minimal comminution }\end{array}$ \\
IIIA & $\begin{array}{l}\text { Laceration }>10 \mathrm{~cm} \\
\text { Edensive soft tissue damage } \\
\text { Segmental/severely comminuted fractures or } \\
\text { heavily contaminated wounds }\end{array}$ \\
\hline III B & $\begin{array}{l}\text { As a Gustilo type IIIA injury, but with } \\
\text { periosteal stripping and bone exposure }\end{array}$ \\
\hline III C & $\begin{array}{l}\text { Any open fracture with vascular injury } \\
\text { requiring repair }\end{array}$ \\
\hline
\end{tabular}

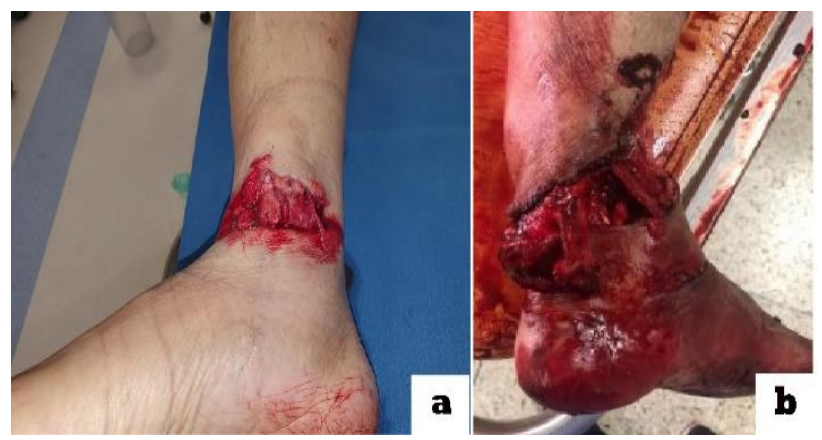

Figure 1: Clinical photographs showing open fractures of the tibial pilon: Gustilo and Anderson type II (a) and type IIIB (b).

\section{Statistical analysis}

Statistical analysis was performed using the statistical package for the social sciences (SPSS) version 17. Data are expressed as mean \pm standard deviation or median (interquartile range) for quantitative data and as percentages for qualitative data. 


\section{RESULTS}

One hundred nine patients were included with complex tibial pilon fractures in our study.

\section{Surgical procedure}

The patients were given general/regional anaesthesia at the discretion of the anaesthesiologist. All of the surgeries were performed under tourniquet control in supine position.

In open fractures, patients were taken to surgery on admission for thorough irrigation and debridement with excision of highly contaminated or necrotic soft tissue as well as non-viable bone, in order to create an environment favourable to healing and to decrease infection risk.

The aim of surgery was to perform anatomical reduction of the joint surface, and provide stability of the fracture to allow return to functional exercise as early as possible. The first step was restoring the length of the fibula. Posterolateral incision over the fibula was performed, followed by one-third tubular plate 3.5 fixation after reduction in 64 patients. Percutaneous fibular pinning was used in 30 patients. The second step involved tibial fracture reduction by applying a longitudinal traction to disimpact the fracture, then K-wires are passed percutaneously or through open wound after its debridement and used as 'joystick' to obtain fracture reduction and provide temporary stabilisation before being sequentially replaced with one to two cortical or cancellous screws. Finally, the tibial fracture is fixed by using a monoplanar external fixator, either spanning the ankle $(48 \%)$ or not $(52 \%)$ depending on the fracture pattern. In case of use of an orthofix external fixator, the distal pins were kept away $14 \mathrm{~mm}$ from the joint line to avoid infection in the ankle joint. Afterwards, intraoperative radiographs were obtained to evaluate the final reduction. However, due to the extensive articular comminution that was sometimes seen, anatomical joint reduction was not always possible.

Next, definitive wound cover was performed at $48 \mathrm{~h}$ for all open fractures. All Gustilo-Anderson type IIIA wounds were closed with delayed primary closure. A fasciocuta neous flap was used to close the Gustilo-Anderson type IIIB wound.

Intraoperative procedures and related radiographs of two fracture cases are shown in (Figure 2 and 3).

\section{Post-operative care and rehabilitation}

Anti-thrombotic treatment with low molecular weight heparin was administered to all patients until resumption of normal ambulation. Strict elevation of the injured limb is very helpful to decrease swelling. All the patients were taught pin tract care.
Active range of motion exercise was started after 3-5 days postoperatively in 102 patients, except in seven patients where the fixation was not rigid enough to mobilize them early.

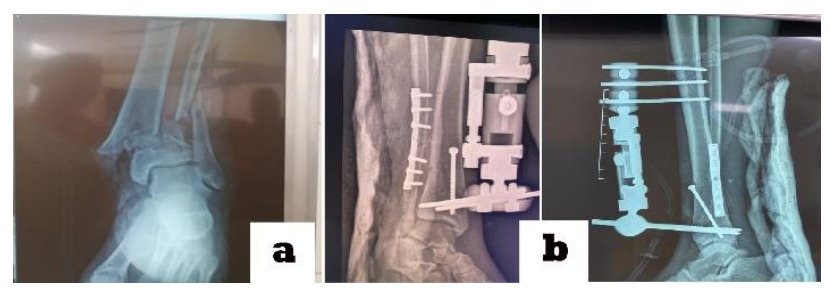

Figure 2: An illustrative case treated with external fixation method and minimally invasive osteosynthesis; (a) Preoperative radiographs of the injured ankle. Initial postoperative radiographs (b) following application of an Orthofix external fixator and a percutaneous cortical screw. Fibular fracture was fixed by a one-third tubular plate.

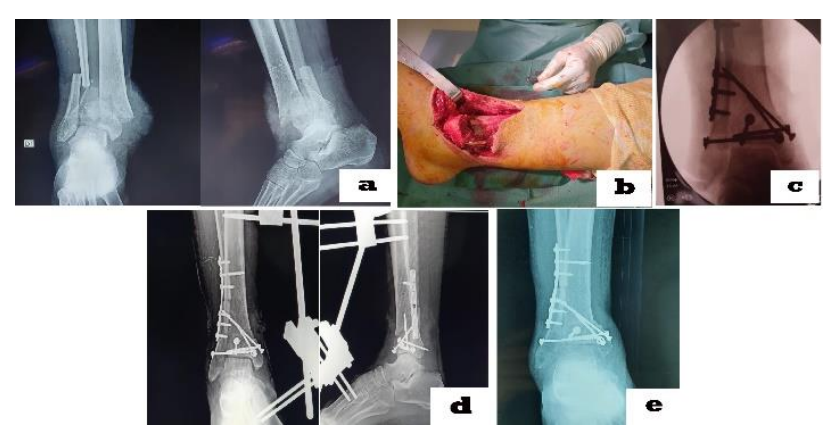

Figure 3: An illustrative case of a 41 years old male with type II open complex tibial pilon fracture : (a)

Preoperative anteroposterior and lateral ankle radiographs showing a C3 type (AO/OTA) tibial pilon fracture, (b) Per-operative visualization of bone fragments, (c) Intraoperative radiographs after fibular plating and screw fixation of pilon fracture, (d) Immediate postoperative $\mathrm{X}$-rays showing reduction and fixator in situ, (e) 13-week follow-up Xrays of same patients showing maintained join congruity after external fixator removal.

All patients were nonweight bearing for 6 weeks postoperatively, and depending on articular surface comminution, were allowed to weight bear progressively from the 6th or 8th week. Full weight bearing was started after clinical and radiological signs of union appeared.

At follow-up, radiographs of the ankle were obtained in the anteroposterior and lateral planes to assess the articular congruity, the metaphyseo-diaphyseal alignment, and any evidence of new arthritic changes. Patients were called for review at 2 weeks, 4 weeks, 8 weeks, 12 weeks, and at monthly intervals thereafter till bony union and maximal functional recovery, to assess the fracture healing and ankle joint movements. The union of the fracture was defined as the presence of a bridging callus in at least three cortices based on the radiograph, while meeting the 
requirement of no pain or tenderness over the fracture zone.

The functional outcome was evaluated using the AOFAS score and the mean duration of follow-up was 47 months.

All fractures were managed with external fixation as a definitive treatment. Postoperative length of stay at hospital average was 14.2 days (range 3 to 28 days). All patients showed radiologic union within an average time of 14 weeks (9-19). There were 11 cases $(10 \%)$ of pin tract infection who were successfully treated with oral antibiotics and aggressive pin toilette (Figure 4). The external fixation system was removed, as an outpatient procedure, after complete union of the fracture.

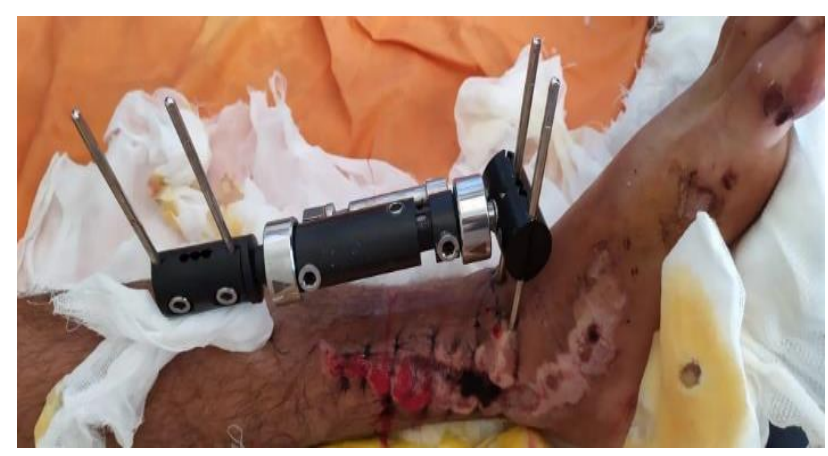

Figure 4: Pin tract infection successfully managed with oral antibiotics and aggressive pin toilette.

One patient developed septic arthritis and required joint irrigation and evidence of radiological osteoarthritis was present in ten cases $(9 \%)$ at final follow-up.

There were no complications of fibular fracture, such as severe infection, skin necrosis, or an exposed plate.

Table 3: Functional outcome by AOFAS score.

\begin{tabular}{|ll|}
\hline AOFAS score & N $(\%)$ \\
\hline Excellent & $50(46)$ \\
\hline Good & $47(43)$ \\
\hline Moderate & $10(9)$ \\
\hline Poor & $2(2)$ \\
\hline
\end{tabular}

In (Table 3) presents the functional outcome assessment in all patients using AOFAS score. The satisfaction rate was $87 \%$. The ten patients with fair outcomes developed slight traumatic arthritis and experienced slight pain during walking.

\section{DISCUSSION}

Tibial pilon fractures represent $1 \%$ of all lower extremity fractures and usually occur due to high-energy trauma, characteristically produced by axial loading which drives the articular surface proximally into the metaphysis, with associated metaphyseal comminution. ${ }^{6}$ Associated fibular fractures are commonly present. Motor vehicle accidents and fall from height are the most frequent mechanisms of injury. ${ }^{7}$

The management of complex tibial pilon fractures is challenging, particularly given that such injuries are usually associated with extensive soft tissue damage even if they are not open fractures and often there is marked comminution of articular surfaces. ${ }^{8}$ There are various surgical options and techniques for managing complex tibial pilon fractures. Essentially, these involve stabilising the fracture using metal devices such as plates and screws with an ORIF procedure, an external fixator or a combination of these. ${ }^{9}$ Although treatment algorithms for these fractures still remain controversial, the goals of intervention remain the same: reestablish limb mechanical alignment, provide stability, and restore articular congruity. ${ }^{10}$ External fixation is less invasive but restoring accurate anatomical reduction can be difficult. Internal fixation is theoretically better at obtaining a more perfect reduction but the risk of soft tissue problems and wound breakdown is higher.

Many external fixation devices are described (conventional frames or circular fine wire fixators) to achieve reduction and fixation of the fragments based on the principle of ligamentotaxis. ${ }^{11}$ The technique of K-wire joysticks is helpful in facilitating reduction of small articular fragments. Temporary stabilization with $\mathrm{K}$-wires also allows an intra-operative check with a $\mathrm{C}$-arm image intensifier, before a definitive stabilization by screws is performed. $^{12}$

Analysing existing literature on this topic must be delicate because most studies refer to a heterogeneous group of patients that include type A and B injuries. ${ }^{10}$

Davidovitch et al retrospectively compared between external fixation and ORIF and concluded that the overall complication and union rates as well as functional outcomes were similar between the two groups. ${ }^{13}$ Wyrsch et al carried out a prospective randomized comparative study between external fixation and ORIF methods, showing superior results in the external fixation group. ${ }^{14}$ Similar findings have been previously reported by Bacon et al in his retrospective analysis of ORIF versus Ilizarov fixation. ${ }^{15}$

Malik-Tabassum et al conducted a systematic review and meta-analysis comparing ORIF with external fixation. ${ }^{16}$ The authors concluded that there was a preference in treating more severe injuries of tibial pilon with external fixation.

A few studies have reported the outcome of external fixation as definitive treatment of complex tibial pilon fractures. 
McDonald et al evaluated 13 pilon fractures (of which 12 were true high-energy injuries) treated with external fixation and minimally invasive materials. ${ }^{17}$ They showed promising results with one delayed union, one case of nonunion and no deep infections.

Wang et al performed a meta-analysis of complications associated with ORIF versus limited internal fixation combined with external fixation. ${ }^{18}$ They found no significant differences in bone healing complications, nonunion, malunion or delayed union, superficial and deep infections, arthritis symptoms or chronic osteomyelitis between the two groups.

Despite this relatively wide interest, general consensus remains absent. Unanswered questions prevail on the superiority of external fixation combined with minimally invasive osteosynthesis in terms of reduced soft tissue complication and their non-inferiority in terms of quality of fracture reduction and stabilisation.

In the present study, we used monolateral external fixator for complex tibial pilon fractures as definitive treatment, which allowed fracture union with functional mobility. The average time to union was of 14 weeks which was comparable to studies by Mitkovic et al and Osman et al. ${ }^{19,3}$ However other factors like open fracture at the time of injury, post-operative infections, smoking habits, and others, do affect the time to union.

Regarding infection, in our series, there were 11 cases of pin tract infections, which is a well-recognised complication associated with external fixation around the ankle. ${ }^{12}$ In metaanalysis by Papadokostakis et al, minor and major infection was observed in $11.7 \%$ and $3.9 \%$ cases respectively, treated with ankle spanning fixator with or without minimally invasive techniques. ${ }^{1}$ Complication rate, mainly infection and wound dehiscence, was found higher $(17 \%)$ in patients with ORIF, as reported by Mcferran et al. ${ }^{20}$

The incidence of osteoarthritis following tibial pilon fractures varies in the literature. Numerous investigators have demonstrated that the occurrence of post traumatic osteoarthritis is mainly due to articular incongruity, and change in mechanical axis. ${ }^{21}$ There was radiological evidence of arthritis in ten of our patients, which was comparable to previously published literature. 3 However, a higher rate $(39 \%)$ was reported by Harris et al at a mean follow up of 26 months after surgery. ${ }^{22}$

Complex tibial pilon fractures are among the most difficult intra-articular fractures to handle and remain a surgical challenge due to the complexity of the fracture patterns. Till date, there is no clear consensus as to the ideal method of treatment. Based on our results, the use of external fixation, combined with minimally invasive osteosynthesis, as primary and definitive, is safe and effective in terms of low rates of complication and good functional results.

\section{CONCLUSION}

The management of colorectal cancer has progressed over the past few decades because of many advances, including those in genetics, pathology, imaging, medical oncology, radiation oncology, and surgery. ${ }^{16}$ Undoubtedly, the management of patients afflicted with colorectal cancer will evolve as advances continue to be made in the multiple disciplines that contribute to the diagnosis and treatment of colorectal cancer.

Funding: No funding sources

Conflict of interest: None declared

Ethical approval: Not required

\section{REFERENCES}

1. Papadokostakis G, Kontakis G, Giannoudis P, Hadjipavlou A. External fixation devices in the treatment of fractures of the tibial plafond. A systematic review of the literature. J Bone Joint Surg [Br]. 2008;(90-B):1-6.

2. Chen $\mathrm{SH}, \mathrm{Wu} \mathrm{PH}$, Lee YS. Long-term results of pilon fractures. Arch Orthop Trauma Surg. 2007;127(1):55-60.

3. Osman W, Alaya Z, Kaziz H, Hassini L, Braiki M, Naouar $\mathrm{N}$ et al. Treatment of high-energy pilon fractures using the ILIZAROV treatment. Pan Afr Med J. 2017;27:199.

4. Dunbar RP, Barej DP, Kubiak EN, Nork SE, Henley MB. Early limited internal fixation of diaphyseal extensions in select pilon fractures: upgrading AO/OTA type $\mathrm{C}$ fractures to AO/OTA type B. J Orthop Trauma. 2008;22:426-9.

5. Gardner MJ, Mehta S, Barei DP, Nork SE. Treatment protocol for open AO/OTA type C3 pilon fractures with segmental bone loss. J Orthop Trauma. 2008;22:451-7.

6. Villaseñor Villaseñor LE, Olea Leyva MA, Rodríguez Flores R, Hernández López JL. Clinical outcome of a bilateral tibial pylon fracture treated with a minimally invasive technique. Acta Ortop Mex. 2009;23(3):163-6.

7. Galante VN, Vicenti G, Corina G, Mori C, Abate A, Picca $G$ et al. Hybrid external fixation in the treatment of tibial pilon fractures: A retrospective analysis of 162 fractures. Injury. 2016;47(4):S131-7.

8. Mauffrey C, Vasario G, Battiston B, Lewis C, Beazley J, Seligson D. Tibial pilon fractures: a review of incidence, diagnosis, treatment, and complications. Acta Orthop Belg. 2011;77(4):432-40.

9. Kapoor SK, Kataria H, Patra SR, Boruah T. Capsuloligamentotaxis and definitive fixation by an ankle-spanning Ilizarov fixator in high-energy pilon fractures. J Bone Joint Surg [Br]. 2010;92(8):1100-6.

10. 1Jacob N, Amin A, Giotakis N, Narayan B, Nayagam $\mathrm{S}$, Trompeter AJ.Management of high-energy tibial pilon fractures. Strat Traum Limb Recon. 2015;10:137-47. 
11. Bear J, Rollick N, and Helfet D. Evolution in Management of Tibial Pilon Fractures. Curr Rev Musculoskelet Med. 2018;11(4): 537-45.

12. Meena UK, Bansal MC, Behera P, Upadhyay R, and Gothwal GC. Evaluation of functional outcome of pilon fractures managed with limited internal fixation and external fixation: A prospective clinical study. J Clin Orthop Trauma. 2017;8(2):S16-20.

13. Davidovitch RI, Elkhechen RJ, Romo S, Walsh M, Egol KA. Open reduction with internal fixation versus limited internal fixation and external fixation for high grade pilon fractures (OTA type 43C). Foot Ankle Int. 2011;32(10):955-61.

14. Wyrsch B, McFerran MA, Mc Andrew M. Operative treatment of fractures of the tibial plafond. A randomized, prospective study. J Bone Joint Surg Am. 1996;78-A:1646-7.

15. Bacon S, Smith WR, Morgan SJ, Hasenboehler E, Philips G, Williams A et al. A retrospective analysis of comminuted intra-articular fractures of the tibial plafond: Open reduction and internal fixation versus external Ilizarov fixation. Injury. 2008;39(2):196-202.

16. Malik-Tabassum K, Pillai K, Hussain Y, Bleibleh S, Babu S, Giannoudis PV et al. Post-operative outcomes of open reduction and internal fixation versus circular external fixation in treatment of tibial plafond fractures: A systematic review and metaanalysis. Injur. 2020;51(7):1448-56.

17. McDonald MG, Burgess RC, Bolano LE, Nicholls PJ. Ilizarov treatment of pilon fractures. Clin Orthop Relat Res. 1996;325:232-8.
18. Wang D, Xiang JP, Chen XH, Zhu QT. A metaanalysis for postoperative complications in tibial plafond fracture: open reduction and internal fixation versus limited internal fixation combined with external fixator. J Foot Ankle Surg. 2015;54(4):646-51.

19. Mitkovic MB, Bumbasirevic MZ, Lesic A, Golubovic $\mathrm{Z}$.Dynamic external fixation of comminuted intra-articular fractures of the distal tibia (type $\mathrm{C}$ pilon fractures). Acta Orthop Belg. 2002;68(5):508-14.

20. McFerran MA, Smith SW, Boulas HJ, Schwartz HS. Complications encountered in the treatment of pilon fractures. J Orthop Trauma. 1992;6:195-200.

21. Thordarson DB. Complications after treatment of tibial pilon fractures: prevention and management strategies. J Am Acad Orthop Surg. 2000;8(4):253-65.

22. Harris AM, Patterson BM, Sontich JK. Results and outcomes after operative treatment of high-energy tibial plafond fractures. Foot Ankle Int. 2006;27:256-5.

Cite this article as: Lemsanni M, Najeb Y, Chafik R, Madhar M, Elhaoury H. Outcome of complex tibial pilon fractures definitively treated with external fixator. Int J Res Orthop 2020;6:1145-50. 